(C) 2022, The Authors. Published by Elsevier Inc. and Fass Inc. on behalf of the American Dairy Science Association ${ }^{\circledR}$. This is an open access article under the CC BY license (http://creativecommons.org/licenses/by/4.0/).

\title{
Photoprotective effects of sphingomyelin-containing milk phospholipids in ultraviolet B-irradiated hairless mice by suppressing nuclear factor-kB expression
}

\author{
Yejin Ahn, ${ }^{1} \odot$ Min G. Kim, ${ }^{1} \odot$ Yong J. Choi, ${ }^{2}$ Sang J. Lee, ${ }^{3}$ Hyung J. Suh, ${ }^{1,4} \oplus$ and Kyungae Jo ${ }^{1 *} \odot$ \\ ${ }^{1}$ Department of Integrated Biomedical and Life Science, Graduate School, Korea University, Seoul 02841, Republic of Korea \\ ${ }^{2}$ Solus Advanced Materials Co., Ltd., Yongin 16858, Republic of Korea \\ ${ }^{3}$ Holistic Bio Co., Ltd., Seongnam 13494, Republic of Korea \\ ${ }^{4}$ Transdisciplinary Major in Learning Health Systems, Department of Healthcare Sciences, Graduate School, Korea University, Seoul 02841, \\ Republic of Korea
}

\section{ABSTRACT}

Ceramide-containing phospholipids improve skin hydration and barrier function and are ideal for use in skin care products. In this study, we evaluated the photoprotective effect of milk phospholipids on the skin condition of UVB-irradiated hairless mice. Skin parameters were assessed following oral administration of milk phospholipids. The UVB irradiation induced photoaging in mice. The animals were divided into 5 groups: a control group (oral administration of saline with no UBV irradiation), UVB group (oral administration of saline with UVB irradiation), and 3 UVB irradiation groups receiving the milk phospholipids at 3 different concentrations of oral administration, $50 \mathrm{mg} /$ $\mathrm{kg}$ (ML group), $100 \mathrm{mg} / \mathrm{kg}$ (MM group), and $150 \mathrm{mg} /$ $\mathrm{kg}$ (MH group), for 8 wk. An increase in skin hydration and transepidermal water loss were improved in the $150 \mathrm{mg} / \mathrm{kg}$ of milk phospholipid-administered group. Hematoxylin and eosin staining revealed a decrease in epidermal thickness in the milk phospholipid-administered groups (50, 100, and $150 \mathrm{mg} / \mathrm{kg}$ of body weight). In particular, the 100 and $150 \mathrm{mg} / \mathrm{kg}$ groups showed significant changes in the area, length, and depth of the wrinkles compared with the UVB group. Moreover, the gene expression of matrix metalloproteins was attenuated, and that of proinflammatory cytokines, especially tumor necrosis factor- $\alpha$, was significantly reduced in the milk phospholipid-administered groups than in the UVB group. The reduced ceramide and increased sphingosine-1-phosphate levels in the skin tissue due to UVB exposure were restored to levels similar to those of the control group following milk phospholipid administration. These results were confirmed to be due to the downregulation of protein expression of nuclear factor

Received August 23, 2021.

Accepted November 16, 2021.

*Corresponding author: kyungae11@korea.ac.kr

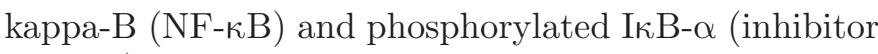
of $\kappa \mathrm{B} \alpha$ ). Collectively, oral administration of milk phospholipids improves skin health through a synergistic effect on photoprotective activity.

Key words: milk phospholipid, photoprotective activity, nuclear factor- $\kappa \mathrm{B}(\mathrm{NF}-\kappa \mathrm{B})$, ultraviolet $\mathrm{B}$ irradiation

\section{INTRODUCTION}

The skin ages similar to other organs in the body. Aging is divided into intrinsic aging, which occurs when human body functions deteriorate and physiological functions such as hormones change, and extrinsic aging, which occurs upon exposure to various environmental factors including UVB rays. Among them, photoaging induced by UVB rays is the most direct cause of extrinsic aging, and typical phenomena include dry skin, wrinkles, decreased skin elasticity, and pigmentation (Woodby et al., 2020; Krutmann et al., 2021). Skin moisture is the most important factor in maintaining skin health and controlling aging. Lack of adequate skin moisture prevents activation of enzymes that are involved in the generation of lipids and natural moisturizing factors, leading to dry and thick stratum corneum of the skin (Bouwstra et al., 2021). The skin comprises the epidermis, dermis, and subcutaneous tissue. The stratum corneum of the epidermis, which is the outermost layer of the skin, is composed of the following 3 main lipids: ceramide (50\%), free fatty acids (25\%), and cholesterol (25\%; Wartewig and Neubert, 2007). Lipids, which form a lamellar structure in the spaces between keratinocytes, act as a barrier to water permeation, preventing water transpiration and the invasion of external factors. The ceramide content in this lipid layer is extremely high. Sphingomyelin in the skin granular layer is hydrolyzed by sphingomyelinase to produce ceramide (Mizutani et al., 2009; Vávrová et al., 2017). 
Milk contains approximately $4 \%$ lipids, and most of them are dispersed in milk in the form of fat globules. These fat globules are covered with a thin membrane called the milk fat globule membrane, approximately half of which consists of lipids. Of these lipids, approximately $70 \%$ are triglycerides, approximately $30 \%$ are phospholipids, and trace amounts are cholesterol. Phospholipids in milk consist of lipids with a glycerol or sphingosine backbone (Fong et al., 2007). Sphingomyelin, which accounts for a large amount of milk phospholipids, increases ceramide levels in the body (Ohlsson et al., 2010), which is not only involved in epidermal hydration but also in the maintenance of skin barrier function (Brod, 1991). Dietary sphingomyelin is hydrolyzed to ceramide and sphingosine in the small intestine after ingestion, and a portion of it is reused for sphingolipid synthesis (Schmelz et al., 1994). Sphingolipids upregulate the expression of enzymes involved in ceramide synthesis (Duan et al., 2012) and are involved in the enhancement of ceramide levels in the skin of hairless mice (Haruta-Ono et al., 2012b).

In this study, milk phospholipids used were polar lipids obtained by ethanol treatment of milk whey powder and contained high levels of phospholipids, mainly phosphatidylcholine and phosphatidylethanolamine, and sphingolipids, mainly sphingomyelin (Lee et al., 2020). Milk phospholipids are a food material rich in ceramide precursors that can protect the skin from UVB rays. Therefore, milk phospholipids were orally administered to UVB-irradiated hairless mice to evaluate its photoprotective effects.

\section{MATERIALS AND METHODS}

\section{Materials and Animals}

Milk phospholipids were obtained from Solus Advanced Materials Co., Ltd. and consisted of $25.0 \pm$ $5.0 \%$ (mean $\pm \mathrm{SD}$ ) of phospholipids $(7.5 \pm 1.5 \%$ of phosphatidylcholine, $6.5 \pm 1.5 \%$ of phosphatidylethanolamine, $1.3 \pm 0.7 \%$ of phosphatidylserine, and $6.5 \pm$ $1.0 \%$ of sphingomyelin), $1.5 \pm 0.5 \%$ of lactosylceramide, $0.9 \pm 0.6 \%$ of glucosylceramide, and $0.3 \pm 0.1 \%$ of GD3 ganglioside (Supplemental Table S1; https://doi.org/10 .6084/m9.figshare.17157776.v1; Jo, 2021).

Male hairless mice (Skh: HR-a, 8 wk old) were purchased from the Central Lab Animal Inc. and subjected to a 1-wk acclimatization period. The breeding environment of the experimental animals was maintained at 23 $\pm 2^{\circ} \mathrm{C}, 55 \pm 10 \%$ humidity, and a 12 -h light-dark cycle. Mice were fed with a mouse-only feed (Purina), and drinking water was provided ad libitum. The breeding and management of mice was based on the Guide for the Care and Use of Laboratory Animals, and this study was approved by the Institutional Animal Care and Use Committee at Korea University (KUIACUC-2020-0054).

\section{Experimental Design}

Hairless mice were randomly divided into 5 groups (6 mice/group) based on their average BW. Mice were divided into oral administration of saline without UVB irradiation (control), oral administration of saline with UVB irradiation (UVB), oral administration of lowdose milk phospholipids with UVB irradiation (ML), oral administration of medium-dose milk phospholipids with UVB irradiation (MM), and oral administration of high-dose milk phospholipids with UVB irradiation (MH) groups. Once daily, mice in groups ML, MM, and $\mathrm{MH}$ were orally administered 50, 100, and $150 \mathrm{mg} /$ $\mathrm{kg}$ of BW of milk phospholipids, respectively.

To induce photoaging, UVB and milk phospholipidadministered mice (ML, MM, and $\mathrm{MH}$ ) were irradiated with UVB at the same time, 3 times per week, using a UVB lamp (UB800, Waldman Licht Technik GmbH). Mice were exposed to 1 minimal erythemal dose (MED; $75 \mathrm{~mJ} / \mathrm{cm}^{2}$ ) in the first and second weeks, 2 MED in the third week, 3 MED in the fourth week, and 4 MED from the fifth week onwards. Milk phospholipids were orally administered with UVB exposure for a total of 8 wk, and mice were killed using $\mathrm{CO}_{2}$ gas after the end of the experiment.

\section{Measurement of Skin Hydration Level, Transepidermal Water Loss, and Wrinkle Formation}

Skin hydration level and transepidermal water loss (TEWL) were measured using a Corneometer CM825 (Courage and Khazaka Electronic $\mathrm{GmbH}$ ) and Tewameter TM300 (Courage and Khazaka electronic $\mathrm{GmbH}$ ), respectively. The dorsal side of the animal was photographed with a digital camera (EOS 600D, Canon), and a replica was generated using a silicone polymer (SILFLO impression material, Flexico) for wrinkle analysis and evaluation. The skin template was fixed at an incident angle of light of $20^{\circ}$, and the wrinkle shadow contrast image was photographed using the Visioline program, imaged, and analyzed using the Skin Viosiometer SV600 software (Courage and Khazana Electronic $\mathrm{GmbH}$ ). The area, number, length, and depth of the wrinkles were determined.

\section{Histopathological Analysis}

After killing the animals, the dorsal skin was incised, attached to filter paper, and fixed in 10\% neutral 
formalin for hematoxylin and eosin and immunohistochemical staining. Tissues were paraffin-embedded by the general tissue processing method, and $6-\mu \mathrm{m}$ sections were cut and stained with hematoxylin and eosin. Immunohistochemical analysis for collagen was performed as described by Yamamoto et al. (2008) using rabbit anti-type I collagen antibodies (1:400; Abcam). All histopathological analyses were performed using a stereomicroscope (Axio Zoom v.16; Carl Zeiss) and the ImageJ software (version 1.8.0; National Institutes of Health).

\section{RNA Extraction and Real-Time Quantitative PCR}

Total RNA was extracted from the skin tissues using TRIzol (Life Technologies Inc.) as per the manufacturer's instructions. Complementary DNA was synthesized from $1 \mu \mathrm{L}$ of RNA of each sample using the iScript cDNA Synthesis kit (Bio-Rad Laboratories Inc.). To determine mRNA expression of genes encoding MMP, TIMP, and proinflammatory cytokines, realtime quantitative PCR was performed using primers used in a previous study (Suh et al., 2020) and SYBR Green (iQ SYBR Green Supermix, Bio-Rad Laboratories, Inc.). The target gene information was as follows: Mmp2 (NM_008610.3), Mmp3 (NM_010809.1), Mmp9 (NM_013599.4), Mmp13 (NM_008607.2), Timp1 (NM_011593.2), Timp2 (NM_011594.3), Il4 (NM_021283.2), Il6 (NM_031168.1), Il10 (NM_010548.2), and Tnfa (NM_013693.3). Data were analyzed by the comparative cycle threshold $\left(2^{-\Delta \Delta \mathrm{C}_{\mathrm{T}}}\right)$ method (Livak and Schmittgen, 2001), and results were normalized to Gapdh mRNA levels.

\section{Analysis of Ceramide by High Performance Thin-Layer Chromatography}

Skin tissues $(100 \mathrm{mg}$ ) were homogenized by adding $1 \mathrm{~mL}$ of chloroform and methanol (2:1, vol/vol). After centrifugation $\left(2,800 \times \mathrm{g}, 10 \mathrm{~min}\right.$ at $\left.25^{\circ} \mathrm{C}\right)$, a chloroform layer was obtained, and the solution was volatilized and used as the sample (Shimoda et al., 2012). High performance thin-layer chromatography silica gel plates $(10 \times 20 \mathrm{~cm}$, Merck $)$ were used to separate the ceramide mixture (Matreya LLC) and samples in the following solvent conditions: chloroform:methanol: water $(40: 10: 1)$ to $2.0 \mathrm{~cm}$, chloroform:methanol:acetic acid (94:4:1.5), from 2.0 to $7.0 \mathrm{~cm}$, and $N$-hexane: diethyl ether:acetic acid (65:35:1), from $7.0 \mathrm{~cm}$ to the top. Then, $3 \%$ (wt/vol) aqueous cupric acetate containing $8 \%$ ( vol/vol) phosphoric acid was dispensed, and the ceramide content was analyzed after drying in an oven at $160^{\circ} \mathrm{C}$ for $15 \mathrm{~min}$ (Uchida et al., 2000).

\section{Analysis of Sphingosine-1-Phosphate by HPLC}

Extraction and derivatization of sphingosine1-phosphate (S1P) from skin tissues was performed as described by Min et al. (2002) and Kim et al. (2011), with some modifications. Skin tissues (100 mg) were homogenized by adding $500 \mu \mathrm{L}$ of PBS and centrifugation at $4,800 \times g$ for $5 \mathrm{~min}$ at $25^{\circ} \mathrm{C}$. The $\mathrm{pH}$ was adjusted to 10 to 11 by adding $700 \mu \mathrm{L}$ of methanol, 300 $\mu \mathrm{L}$ of $1 M \mathrm{NaCl}, 600 \mu \mathrm{L}$ of $\mathrm{CHCl}_{3}$, and then $35 \mu \mathrm{L}$ of $6 \mathrm{~N} \mathrm{NaOH}$. After centrifugation of the sample $(4,800 \times$ $g, 5 \mathrm{~min}$ at $25^{\circ} \mathrm{C}$ ), the lower layer was obtained, and the solution was volatilized. Then, the samples were added to $500 \mu \mathrm{L}$ of $0.15 \mathrm{M}$ methanolic $\mathrm{KOH}$ and vortexed at $37^{\circ} \mathrm{C}$ for $20 \mathrm{~min}$. After, we added the solution to 500 $\mu \mathrm{L}$ of $\mathrm{CHCl}_{3}, 100 \mu \mathrm{L}$ of $2 \mathrm{~N} \mathrm{NH}_{4} \mathrm{OH}$, and $400 \mu \mathrm{L}$ of alkaline water $\left(100 \mu \mathrm{L} 2 \mathrm{~N} \mathrm{NH} \mathrm{NH}_{4} \mathrm{OH} / 00 \mathrm{~mL}\right.$ water $)$, and vortexed at $37^{\circ} \mathrm{C}$ for $1 \mathrm{~h}$. After centrifugation at $4,800 \times g$ for $3 \mathrm{~min}$ at $25^{\circ} \mathrm{C}$, washing twice with 800 $\mu \mathrm{L}$ of alkaline water, and volatilizing the solution, the obtained lipid extraction samples were dissolved in 120 $\mu \mathrm{L}$ of methanol. The $o$-phthalaldehyde derivatization reagent [Sigma; $50 \mathrm{mg}$ of ortho-phthalaldehyde, $1 \mathrm{~mL}$ of ethanol, $100 \mu \mathrm{L}$ of 2-mercaptoethanol, and $50 \mathrm{~mL}$ of $3 \%$ (wt/vol) boric acid solution] was added to 20 $\mu \mathrm{L}$ of the sample and incubated at $25^{\circ} \mathrm{C}$ for $30 \mathrm{~min}$ for derivatization.

The S1P analysis was performed using the e2695 Waters HPLC system (Waters) equipped with a YMC-Pack Pro C18 column $(4.6 \mathrm{~mm} \times 150 \mathrm{~mm})$ and fluorescence detector (Waters, e2475). The flow rate was $0.5 \mathrm{~mL} /$ min, and the injection volume was $20 \mu \mathrm{L}$. The mobile phase was methanol:distilled water $(92: 8, \mathrm{vol} / \mathrm{vol})$ with $0.1 \%$ triethylamine, and the chromatogram of S1P was analyzed at excitation and emission wavelengths of 340 and $455 \mathrm{~nm}$, respectively. The concentrations of S1P standards (Sigma) were calculated using individual calibration curves (Moon et al., 2013).

\section{Western Blotting}

Protein expression in skin tissues was investigated as previously described (Suh et al., 2020). Antibodies against I $\kappa \mathrm{B} \alpha(1: 1,000, \# 9242$, Cell Signaling Technol-

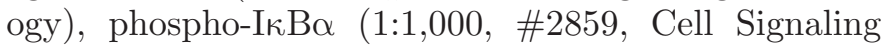
Technology), $\alpha$-tubulin (1:1,000, \#2125, Cell Signaling Technology), NF-кB (1:1,000, \#6956, Cell Signaling Technology), GAPDH (1:1,000, \#5174, Cell Signaling 

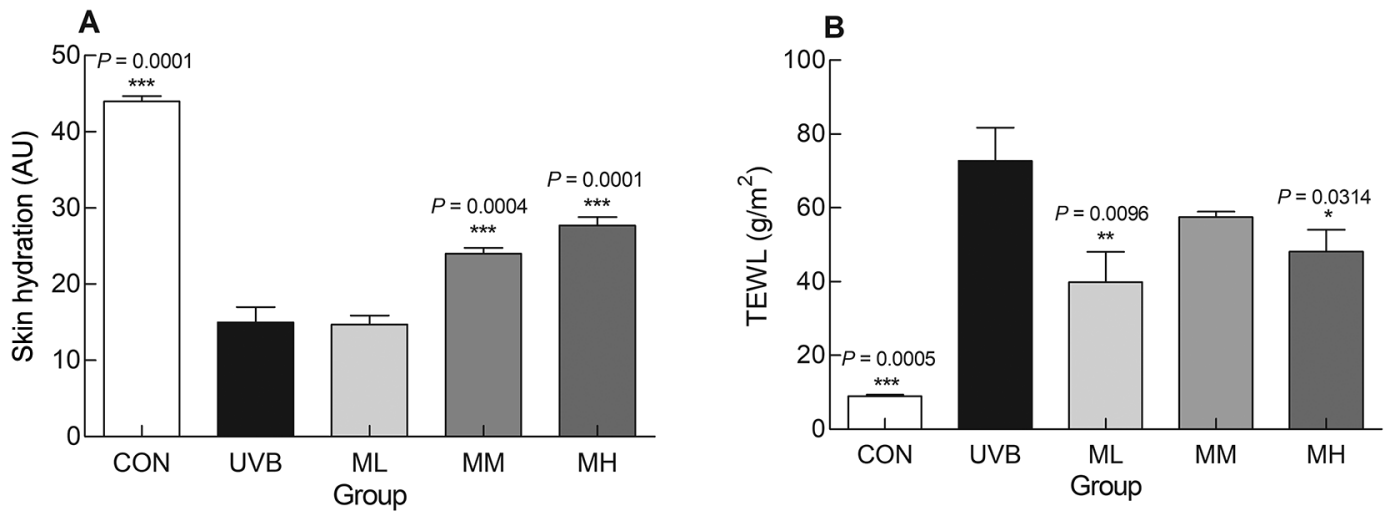

Figure 1. Effects of milk phospholipids on skin hydration (A) and transepidermal water loss (TEWL, B). CON = oral administration of saline with no UVB irradiation; UVB = oral administration of saline with UVB irradiation; ML, MM, and MH = oral administration of low-dose $(50 \mathrm{mg} / \mathrm{kg}$ of BW), medium dose $(100 \mathrm{mg} / \mathrm{kg}$ of BW), and high-dose $(150 \mathrm{mg} / \mathrm{kg}$ of BW) milk phospholipids, respectively, with UVB irradiation. $\mathrm{AU}=$ arbitrary units. Data are expressed as means $\pm \mathrm{SE}(\mathrm{n}=6) .{ }^{*} P<0.05,{ }^{* *} P<0.01$, and ${ }^{* * *} P<0.001$ for control vs. UVB group without milk phospholipids group using Tukey's multiple comparison test.

Technology), and anti-rabbit IgG (1:1,000, \#7074, Cell Signaling Technology) were used.

\section{Statistical Analysis}

The results are expressed as mean and standard error. The significance of data between the UVB and experimental groups was verified by the Tukey's multiple comparison test using SPSS software version 12.0 for Windows (SPSS Inc.).

\section{RESULTS}

\section{Effect of Milk Phospholipids on Skin Hydration and TEWL}

Skin barrier function is an important indicator of skin homeostasis. Thus, skin hydration and TEWL were analyzed. Skin hydration was significantly lower, and TEWL was significantly higher in the UVB group than in the control group (CON, $P=0.0001$ and $P=$ 0.0005, respectively; Figure 1). Milk phospholipid administration suppressed the UVB irradiation-induced decrease in skin hydration and suppressed the increase in TEWL. In particular, skin hydration and TEWL were significantly different between the $\mathrm{MH}$ and UVB groups $(P=0.0001$ and $P=0.0314$, respectively).

\section{Effect of Milk Phospholipids on Epidermal Thickness and Collagen Distribution}

Hematoxylin and eosin and immunohistochemical staining were performed to evaluate the effect of milk phospholipid intake on epidermal thickness and collagen distribution following UVB irradiation (Figure
2). After 8 wk of UVB irradiation and administration of milk phospholipids, hematoxylin and eosin-stained sections of skin samples obtained from mice were analyzed for epidermal thickening. The thickness of the epidermis was significantly greater in the UVB group than in the nonirradiated control group $(P=0.0001$, Figure 2B). Consistent with visual observations of the hematoxylin and eosin-stained samples, oral administration of milk phospholipids significantly decreased UVB irradiation-induced increase in epidermal thickness $(P=0.0004, P=0.0002$, and $P=0.0001$, respectively) in a dose-dependent manner. In addition, skin of control group had collagen fibers homogenously distributed, and collagen distribution was significantly increased by UVB irradiation, as indicated by collagen distribution ratios of the UVB and control groups $(P$ $=0.0002$, Figure 2D). Collagen distribution tended to decrease in the milk phospholipid-administered groups (ML, MM, and MH), but the difference was not significant.

\section{Effect of Milk Phospholipids on Skin Wrinkle Formation}

To evaluate the inhibitory effect of milk phospholipids on UVB irradiation-induced wrinkle formation, the wrinkle area, mean wrinkle length, and mean wrinkle depth, which are wrinkle-forming factors, were measured (Figure 3). The UVB irradiation caused significant differences in the wrinkle area, mean wrinkle length, and mean wrinkle depth, as indicated by data of the UVB and control groups $(P=0.0001, P=0.0002$, and $P=0.0003)$. Oral administration of medium-dose and high-dose milk phospholipids suppressed UVB irradiation-induced wrinkle formation (area, $P=0.0002$ 
A

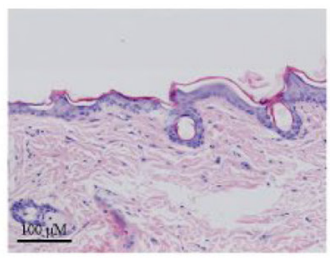

CON

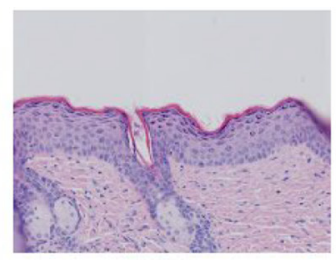

UVB

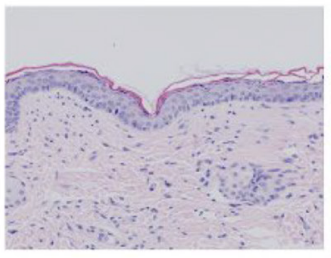

ML

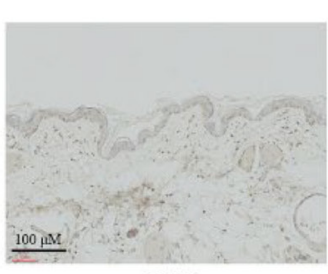

CON

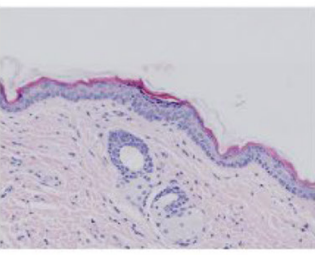

MM

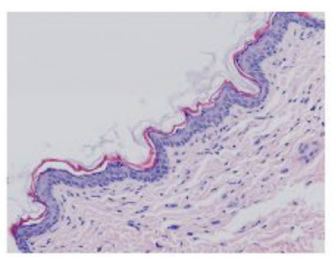

MH

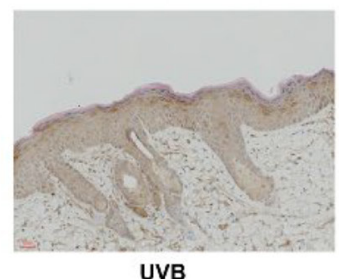

UVB

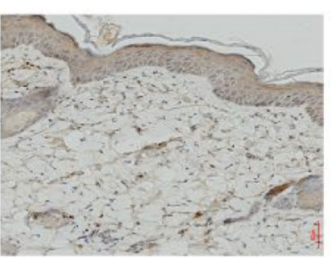

ML

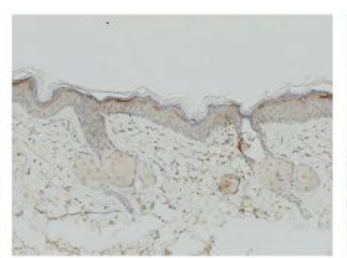

MM

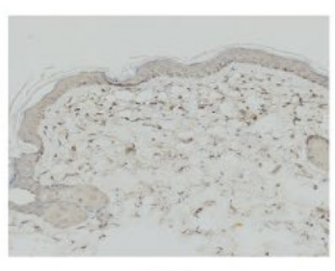

MH
B

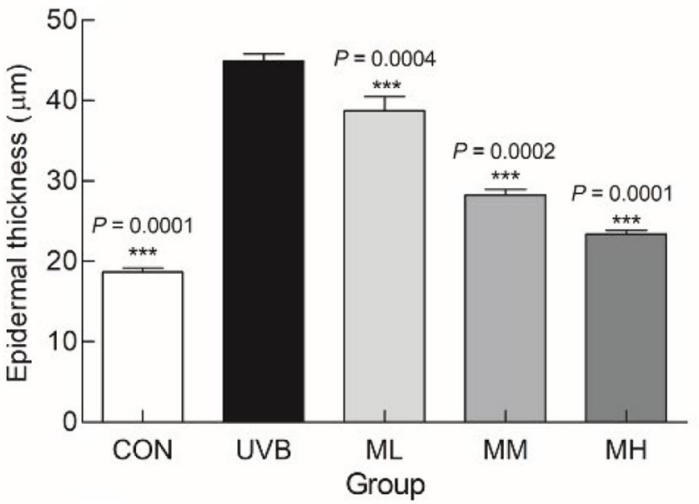

D

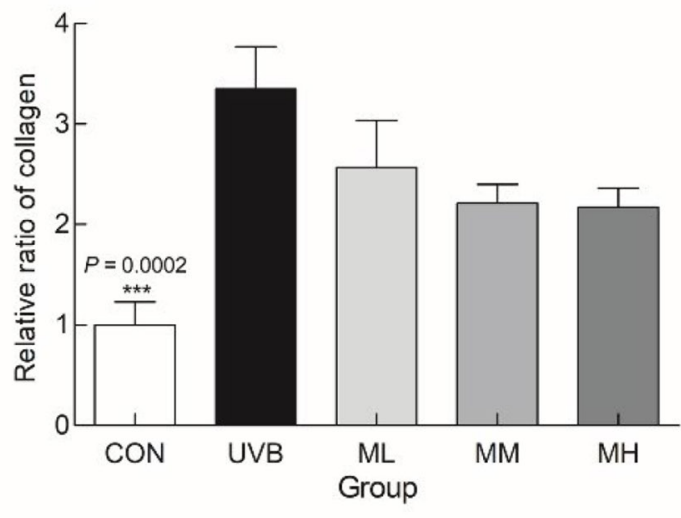

Figure 2. Effects of milk phospholipids on epidermal thickness $(\mathrm{A}, \mathrm{B})$ and relative collagen distribution $(\mathrm{C}, \mathrm{D})$. CON $=$ oral administration

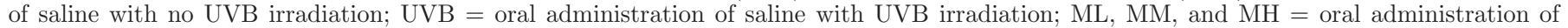

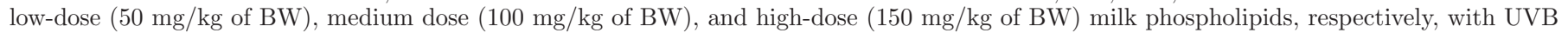

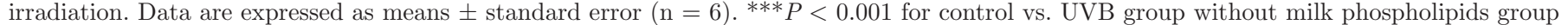
using Tukey's multiple comparison test.

and $P=0.0001$; length, $P=0.0356$ and $P=0.0002$; depth, $P=0.0002$ and $P=0.0002$ ).

\section{Effect of Milk Phospholipids on MMP and TIMP Expression}

The MMP are representative enzymes that degrade extracellular matrix proteins, especially collagen, whereas TIMP inhibit the action of collagen-degrading enzymes (Fisher et al., 1996; Vincenti and Brinckerhoff, 2002). The UVB irradiation increased the expression of genes encoding MMP, promoting wrinkle formation (Figure 4). The expression of Mmp2, Mmp3, Mmp9, and Mmp13 in the UVB group was significantly increased compared with that in the control group because of UVB irradiation (Figure 4, $P=0.0424, P=0.0005$, $P=0.0007, P=0.0001$, respectively). In contrast, the expression of Timp1 and Timp2 was lower in the UVB group than in the control group. Expression of Timp1 in the UVB group was significantly decreased compared with that in the control group $(P=0.0001)$. The UVB irradiation-induced increase in the expression of genes encoding MMP was decreased in the ML, MM, and $\mathrm{MH}$ groups compared with the UVB group. In addition, Timp2 expression in the $\mathrm{MM}$ and $\mathrm{MH}$ groups were higher than that in the UVB group, but there were no significant differences. Oral administration of milk phospholipids was more effective in regulating the expression of genes encoding MMP than genes expressing TIMP.

\section{Effect of Milk Phospholipids on Proinflammatory Cytokine Production}

The mRNA expression of the proinflammatory cytokines Il4, Il6, Il10, and Tnfa after UVB irradiation were 

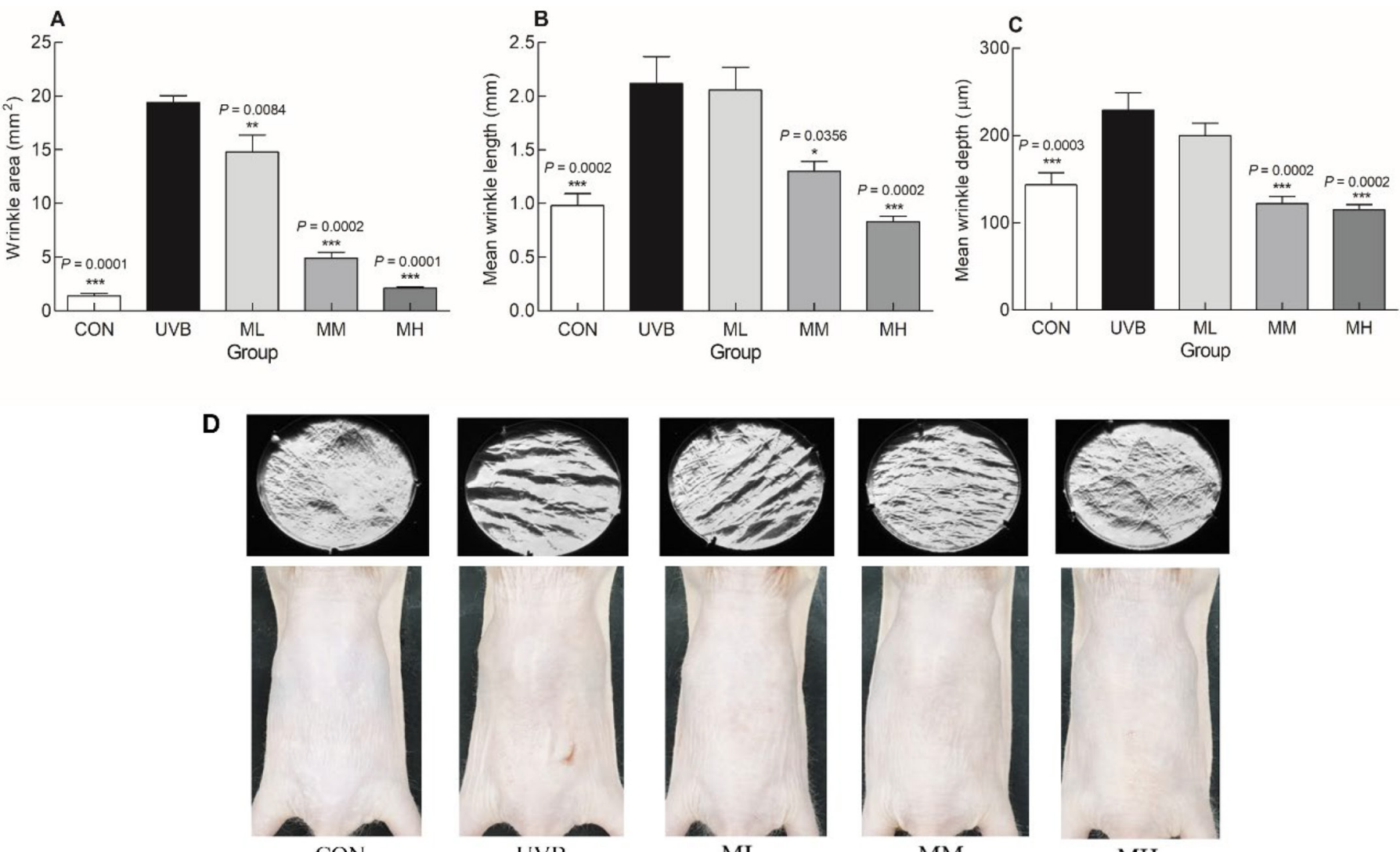

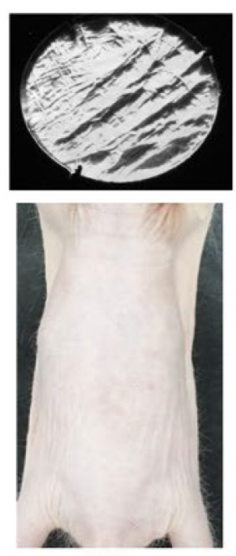

ML
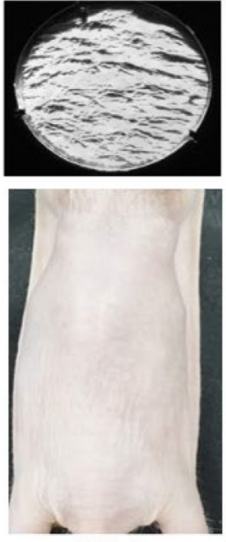

$\mathrm{MM}$
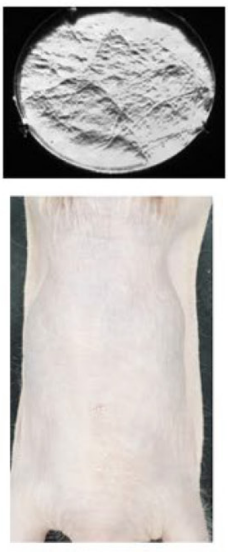

$\mathrm{MH}$

Figure 3. Effects of milk phospholipids on skin wrinkle area (A), mean wrinkle length (B), and mean wrinkle depth (C). Photographs and replicas of the mouse dorsal skin (D). CON = oral administration of saline with no UVB irradiation; UVB = oral administration of saline with UVB irradiation; ML, MM, and MH = oral administration of low-dose (50 mg/kg of BW), medium dose (100 mg/kg of BW), and high-dose (150 $\mathrm{mg} / \mathrm{kg}$ of BW) milk phospholipids, respectively, with UVB irradiation. Data are expressed as means \pm standard error $(\mathrm{n}=6)$. ${ }^{*} P<0.05,{ }^{* *} P$ $<0.01$, and ${ }^{* * *} P<0.001$ for control vs. UVB group without milk phospholipids group using Tukey's multiple comparison test.

significantly increased in the UVB group compared with the control group (Figure 5). The expression of proinflammatory cytokines in the ML, MM, and MH groups was similar to that of the control group, demonstrating the suppression of UVB irradiation-induced increase in proinflammatory cytokine expression. The expression of $1 l 10$, which encodes an immunosuppressive cytokine, was significantly decreased in the ML, $\mathrm{MM}$, and $\mathrm{MH}$ groups compared with the UVB group in a dose-dependent manner (Figure 5C). The expression and function of cytokines that mediate the inflammatory response induced by UVB rays were restored to normal levels by milk phospholipids.

\section{Effect of Milk Phospholipids on Ceramide and S1P Contents in Skin Tissues}

When irradiated with UVB, the ceramide content in the UVB group was lower than that in the control group, but the difference was not significant (Figure $6 \mathrm{~A})$. The UVB irradiation-induced decrease in the ce- ramide content was reversed by milk phospholipids, but the difference was not significant compared with that in the UVB group.

Figure $6 \mathrm{~B}$ shows that the S1P content in the UVB group was significantly increased compared with that in the control group $(P=0.0247)$. Furthermore, milk phospholipids considerably decreased the S1P content compared with the UVB group.

\section{Effect of Milk Phospholipids on NF-kB Activation}

Figure 7 shows protein expression of NF- $\kappa \mathrm{B}$ and $\mathrm{I} \kappa \mathrm{B}$ $[\mathrm{I} \kappa \mathrm{B} \alpha$ and phosphorylated $(\mathbf{p})-\mathrm{I} \kappa \mathrm{B} \alpha]$. The protein levels of NF- $\kappa \mathrm{B}$ and $\mathrm{p}-\mathrm{I} \kappa \mathrm{B} \alpha$ were significantly increased by UVB irradiation, as demonstrated by data of the UVB and control groups $(P=0.0001$ and $P=0.0074$, respectively). The increase in protein level of NF- $\kappa \mathrm{B}$ by UVB irradiation was significantly decreased by milk phospholipids (ML, MM, and MH) in a dose-dependent manner $(P=0.0001, P=0.0001$, and $P=0.0001$, respectively). The increase in protein level of $\mathrm{p}-\mathrm{I} \kappa \mathrm{B} \alpha$ by 
UVB irradiation was also significantly decreased by milk phospholipids (ML, MM, and MH) in a dose-dependent manner $(P=0.0410, P=0.0070$, and $P=0.0001$, respectively). However, the effect of milk phospholipids on the I $\kappa \mathrm{B} \alpha$ protein level showed the opposite trend to the change of the NF- $\kappa \mathrm{B}$ and $\mathrm{p}-\mathrm{I} \kappa \mathrm{B} \alpha$ protein levels. Milk phospholipids reduced the expression of NF- $\kappa \mathrm{B}$, a photoaging inducer of reactive oxygen species (ROS) generated by UVB irradiation, at the protein level.

\section{DISCUSSION}

The milk phospholipids used in this study were polar lipids extracted from whey powder and were composed of phospholipids, mainly phosphatidylcholine and phosphatidylethanolamine, and sphingolipids, mainly sphingomyelin; thus, they were rich in ceramide precursors, which are necessary for moisturizing the skin (Lee et al., 2020). Milk fat is a dietary source of sphingomyelin, and dietary sphingomyelin raises the levels of ceramide in the body. Ceramide plays a role in maintaining the moisture supply of the epidermis and skin barrier function (Parodi, 1997; Graves et al., 2007).

Ceramide accounts for 40 to $60 \%$ of the intercellular lipids (Lodén, 2012) and is known to play a crucial role in skin barrier function and skin moisturization by forming a lamellar structure to support the space between keratinocytes (Boer et al., 2016). Additionally, ceramide levels decrease with age, and the amount also decreases in patients with dry skin or atopic dermatitis (Simpson et al., 2013). Ceramide is recognized as a crucial component in maintaining skin homeostasis.

Skin photoaging caused by UVB exposure over a long period of time causes histological changes, such as irregular changes in keratinocytes, an increase in the number of fibroblasts and inflammatory cells, and an accelerated increase in cross-linked collagen fiber levels in the dermis (Robert et al., 2009). Furthermore, exposure of the skin to UVB also causes ROS production (Ansary et al., 2021; Geng et al., 2021). Exposure to UVB promotes continuous ROS generation in keratinocytes, and ROS are rapidly removed by enzymatic and nonenzymatic methods. However, ROS overgeneration causes skin damage. Free radicals generated from ROS cause deterioration of cell structure and function, which ultimately result in abnormal gene expression in cells. UVB-mediated ROS generation affects mitogenactivated protein kinase signaling. Mitogen-activated protein kinase is known to activate the transcription

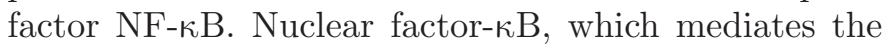
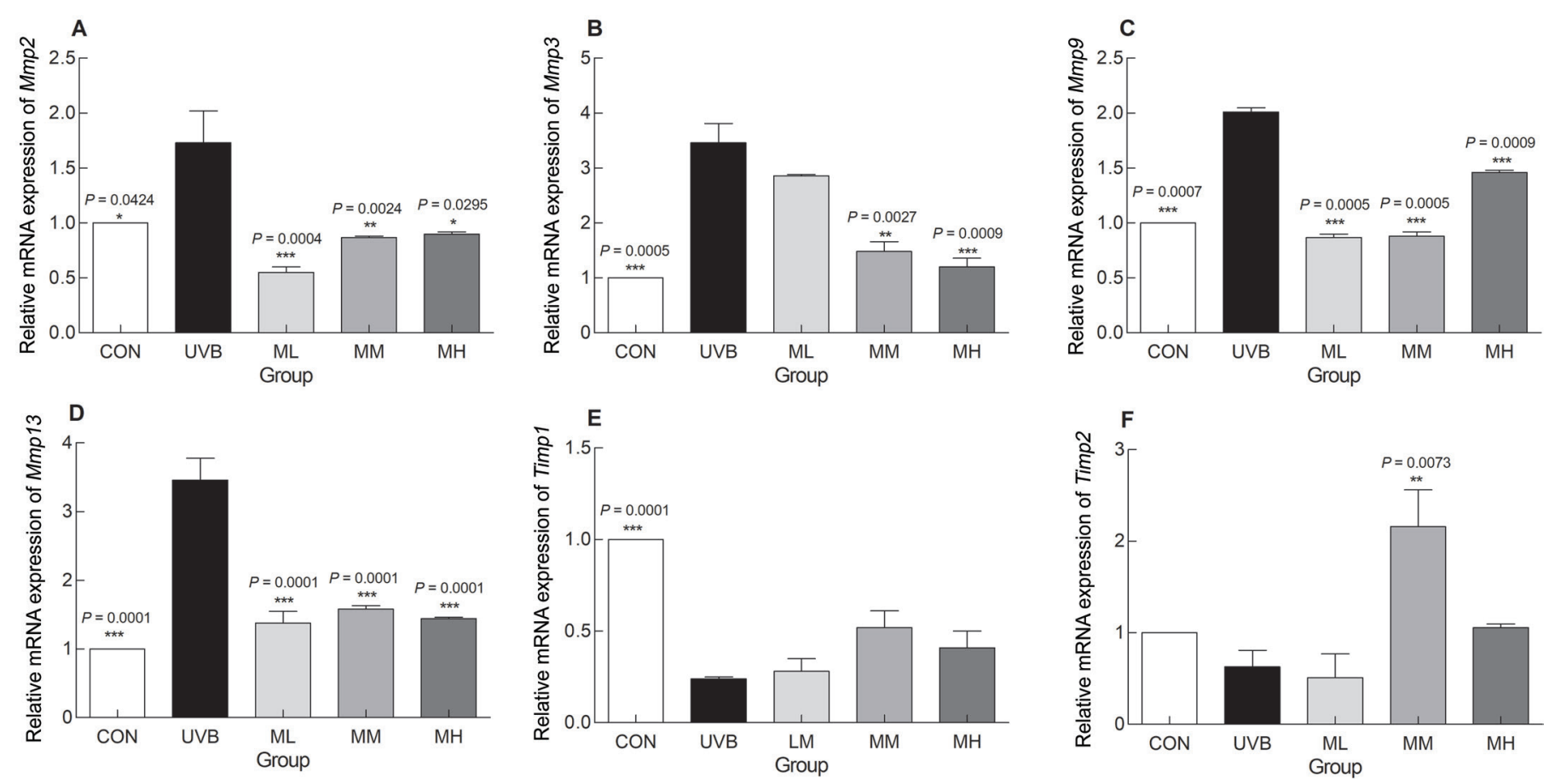

Figure 4. Effects of milk phospholipids on mRNA expression of Mmp2 (A), Mmp3 (B), Mmp9 (C), Mmp13 (D), Timp1 (E), and Timp2 (F). $\mathrm{CON}=$ oral administration of saline with no UVB irradiation; UVB = oral administration of saline with UVB irradiation; ML, MM, and MH $=$ oral administration of low-dose $(50 \mathrm{mg} / \mathrm{kg}$ of BW), medium dose $(100 \mathrm{mg} / \mathrm{kg}$ of BW), and high-dose $(150 \mathrm{mg} / \mathrm{kg}$ of BW) milk phospholipids, respectively, with UVB irradiation. Data are expressed as means \pm standard error $(\mathrm{n}=6)$. ${ }^{*} P<0.05,{ }^{* *} P<0.01$, and ${ }^{* * *} P<0.001$ for control vs. UVB group without milk phospholipids group using the Tukey's multiple comparison test; ns = not significant. 
A

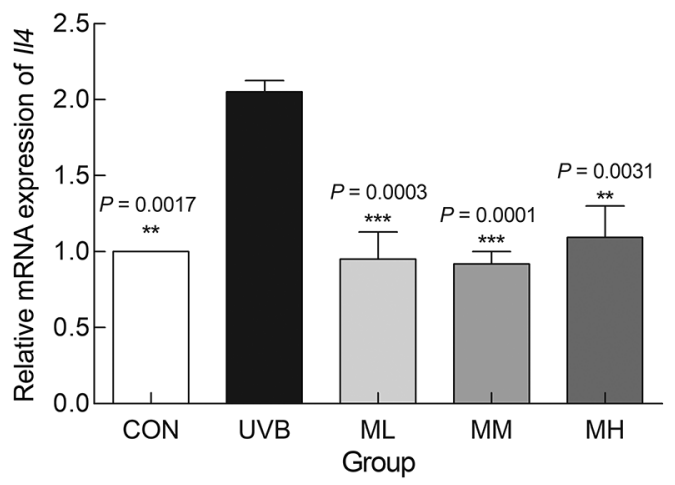

C

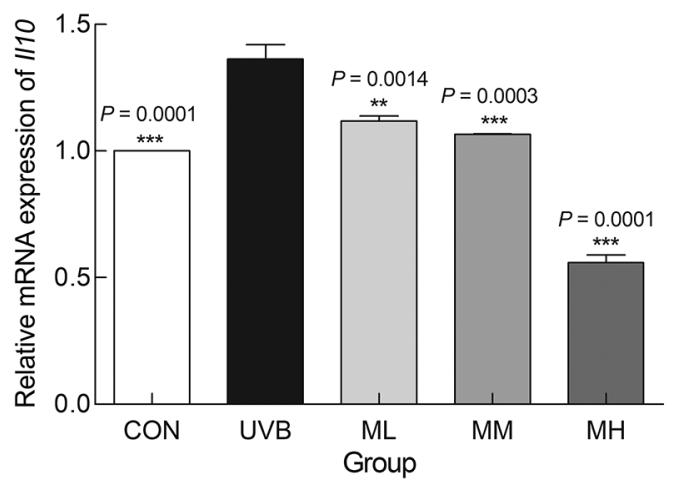

B
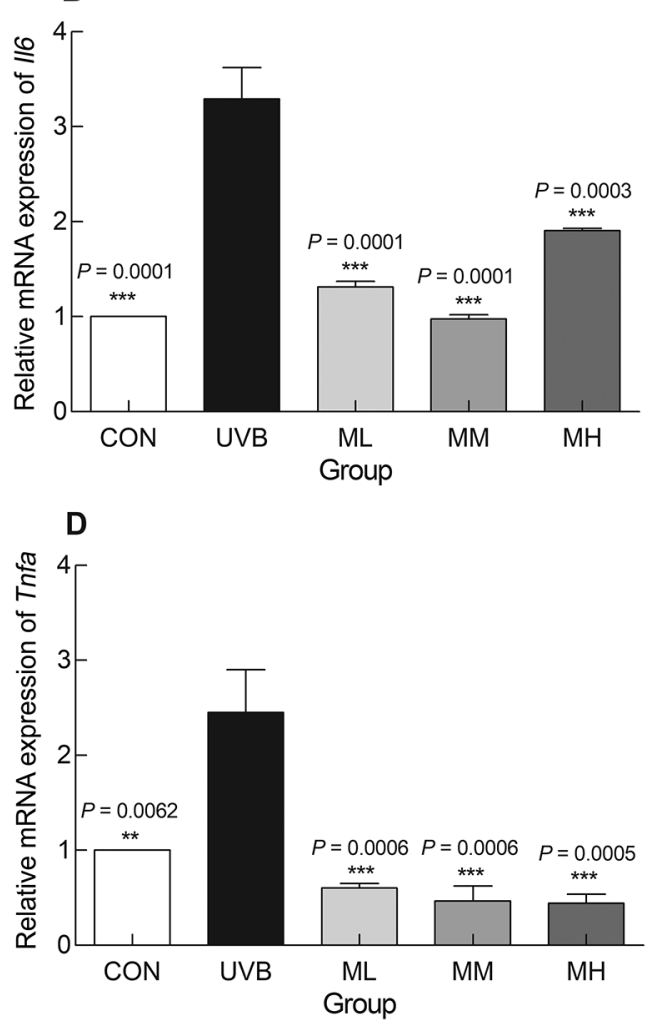

Figure 5. Effects of milk phospholipids on mRNA expression of $I l 4$ (A), Il6 (B), Illo (C), and Tnfa (D). CON = oral administration of saline with no UVB irradiation; UVB = oral administration of saline with UVB irradiation; ML, MM, and MH = oral administration of low-dose (50 $\mathrm{mg} / \mathrm{kg}$ of BW), medium dose $(100 \mathrm{mg} / \mathrm{kg}$ of BW), and high-dose $(150 \mathrm{mg} / \mathrm{kg}$ of BW) milk phospholipids, respectively, with UVB irradiation. Data are expressed as means \pm standard error $(\mathrm{n}=6)$. ${ }^{* *} P<0.01$ and ${ }^{* * *} P<0.001$ vs. UVB group without milk phospholipids group using the Tukey's multiple comparison test.

inflammatory response, binds to an inhibitor of NF$\kappa \mathrm{B}(\mathrm{I} \kappa \mathrm{B})$ and is present in the cytoplasm in an inactive form (Yamazaki et al., 2001; Garg and Aggarwal, 2002). When cells are stimulated, such as UV light, I $\kappa \mathrm{B}$ kinase phosphorylates the inhibitory $\mathrm{I} \kappa \mathrm{B} \alpha$ protein. This phosphorylation results in the dissociation of $I \kappa B \alpha$ from NF- $\kappa$ B. The liberated NF- $\kappa$ B enters the nucleus and activates the transcription of genes involved in immune and inflammatory responses (Yamazaki et al., 2001; Garg and Aggarwal, 2002).

Keratinocytes that are stimulated by ROS secrete proinflammatory cytokines to stimulate dermal fibroblasts by promoting DNA binding of NF- $\kappa \mathrm{B}$ and AP1 , thereby increasing the expression of MMP. On the other hand, MMP attenuates the synthesis of type-1 procollagen, which in turn inhibits collagen biosynthesis and promotes degradation, forming skin wrinkles and reducing elasticity (Gao et al., 2018; Jin et al., 2021).

Oral administration of milk phospholipids significantly decreased the mRNA expression of Mmp2, Mmp3, Mmp13, and the proinflammatory cytokines Il4, Il6, Il10, and Tnfa compared with that of the UVB group.
The decrease in the expression of proinflammatory cytokines suppressed wrinkle formation caused by photoaging. Although there was no significant difference in collagen distribution, there was a considerable decrease when compared with the UVB group. As such, oral administration of milk phospholipids not only decreased the expression of proinflammatory cytokines but also decreased the expression of MMP, thereby inhibiting collagen degradation and suppressing wrinkle formation. Moreover, milk phospholipids exhibited inhibitory effect on UVB irradiation-induced decrease in the skin moisture content and increase in moisture evaporation.

Skin hydration is closely related to the moisture content of the stratum corneum, which is the outermost layer of the epidermis. The stratum corneum has an organic complex structure of proteins and lipids that forms the skin barrier; a decrease in the moisture content of the stratum corneum results in dryness of the skin and abnormalities in skin barrier function (Nisbet, 2018). Furthermore, the main role of ceramide in the stratum corneum is protecting the epidermal barrier, and a decrease in the ceramide content in the stratum 

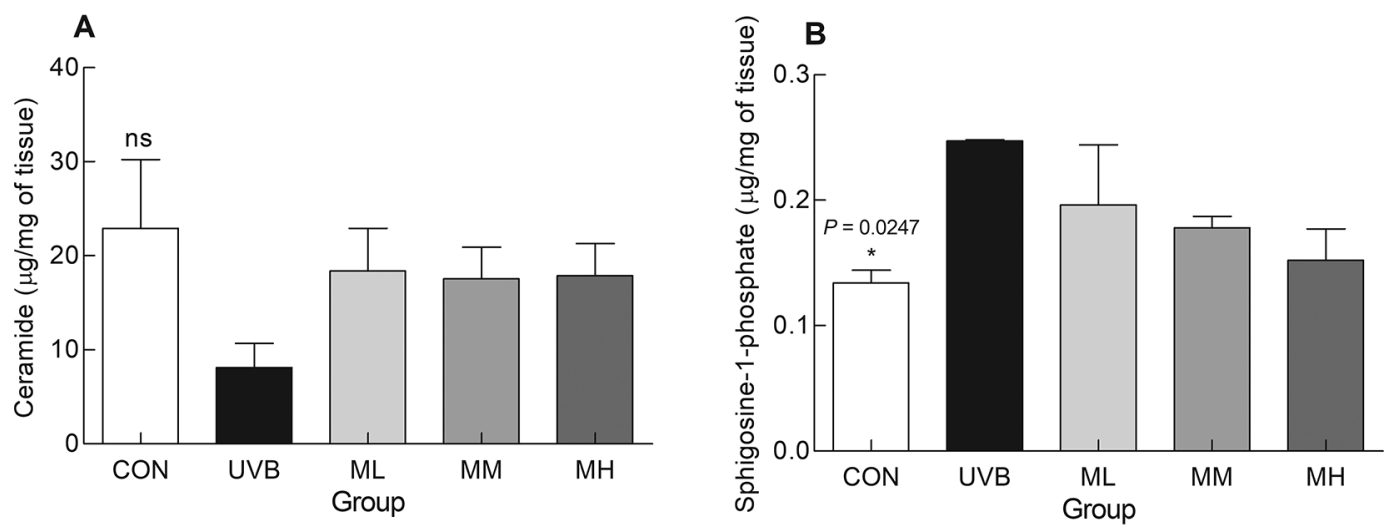

Figure 6. Effects of milk phospholipids on ceramide (A) and sphingosine-1-phosphate (B) contents. CON = oral administration of saline with no UVB irradiation; UVB = oral administration of saline with UVB irradiation; ML, MM, and MH $=$ oral administration of low-dose $(50$ $\mathrm{mg} / \mathrm{kg}$ of BW), medium dose (100 mg/kg of BW), and high-dose (150 mg/kg of BW) milk phospholipids, respectively, with UVB irradiation. Data are expressed as means \pm standard error $(\mathrm{n}=6) . * P<0.05$ vs. UVB group without milk phospholipids group using the Tukey's multiple comparison test; ns = not significant differences between groups.

corneum weakens the skin barrier function and acts as a cause of increased water loss between the skin. Milk ceramide used in this experiment was a raw material rich in phospholipids, and sphingomyelin accounts for 20 to $25 \%$ of milk ceramide (Lee et al., 2020). Sphingomyelin is the main component of mammalian cell membranes and a basic component of the lamellar structure responsible for the barrier function of the skin epidermis. Dietary sphingolipids, such as sphingomyelin and glucosylceramide, reportedly improve the skin barrier function (Tsuji et al., 2006; Duan et al., 2012; HarutaOno et al., 2012a). The content of sphingomyelin, a ceramide precursor, is higher in milk phospholipids than in phospholipids extracted from other foods. Sphingoids are a structural component of sphingomyelin. Their absorption rate based on their source was evaluated in Caco-2 cells, and it was found that the absorption rate of animal-derived sphingoids was higher than that of plant-derived sphingoids. Therefore, sphingomyelin and glucosylceramide, which are sphingolipids, may be effective in strengthening the barrier function of the skin epidermis (Potočki, 2016; Morifuji, 2019).

Ceramides are an important component of the skin barrier and are involved in the prevention of TEWL. They are also important biological metabolites that regulate cellular processes, such as proliferation, differentiation, and apoptosis (Robert et al., 2009; Simpson et al., 2013). Sphingosine-1-phosphate is a sphingolipid

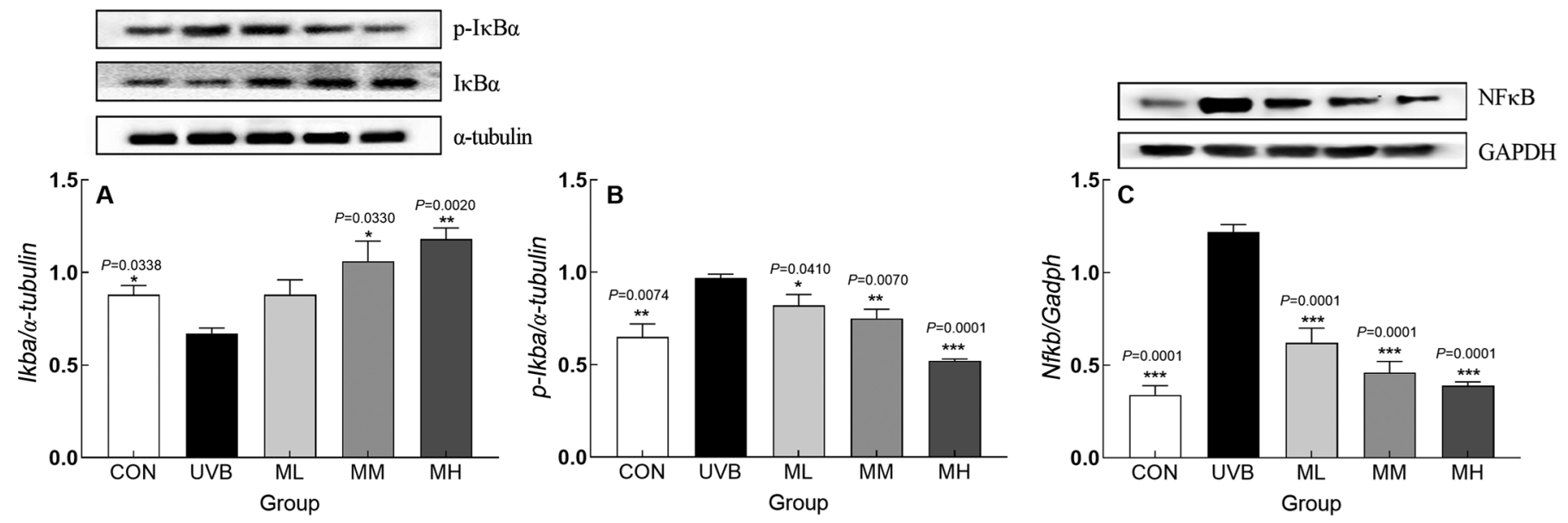

Figure 7. Effects of milk phospholipids on protein expression of $\mathrm{I} \kappa \mathrm{Ba}(\mathrm{A})$, phosphorylated (p)-I $\kappa \mathrm{Ba}(\mathrm{B})$, and nuclear factor (NF)- $\kappa \mathrm{B}(\mathrm{C})$. $\mathrm{CON}=$ oral administration of saline with no UVB irradiation; UVB = oral administration of saline with UVB irradiation; ML, MM, and MH $=$ oral administration of low-dose $(50 \mathrm{mg} / \mathrm{kg}$ of BW), medium dose $(100 \mathrm{mg} / \mathrm{kg}$ of BW), and high-dose (150 mg $/ \mathrm{kg}$ of BW) milk phospholipids, respectively, with UVB irradiation. Data are expressed as means \pm standard error $(\mathrm{n}=6) .{ }^{* *} P<0.01$ and $* * * P<0.001$ vs. UVB group using the Tukey's multiple comparison test. 
with a phosphate group attached to position 1 and is produced from ceramide by ceramidase and sphingosine kinase. It has a special function in epidermal cells and is involved in keratinocyte proliferation, apoptosis, differentiation, and migration. In keratinocytes, S1P acts as an immune response modulator by activating the NF- $\kappa \mathrm{B}$ pathway to increase the production of cathelicidin antimicrobial peptides as effectors of the innate immune response (Park et al., 2013; Jeong et al., 2015). An increase in the dose of milk phospholipids decreased the S1P content, resulting in decreased $N F-\kappa B$ mRNA and protein expression. Interestingly, $\mathrm{NF}-\kappa \mathrm{B}$ is involved in the inflammatory response through various pathways. Therefore, a reduction in $N F-\kappa B$ expression may improve photoaging by reducing the production of proinflammatory cytokines.

\section{CONCLUSIONS}

Phospholipids are representative lipids constituting the skin, and milk phospholipids, with a high phospholipid content, may be used as dietary supplements for skin health. In this study, milk phospholipids were found to suppress the expression of MMP and proinflammatory cytokines through the downregulation of $\mathrm{NF}-\kappa \mathrm{B}$ and $\mathrm{p}-\mathrm{I} \kappa \mathrm{B} \alpha$ protein expression, demonstrating its photoprotective effect against UVB irradiation-induced skin damage in a hairless mouse model. In addition, further studies on the effect of milk phospholipids on ROS are needed in the future.

\section{ACKNOWLEDGMENTS}

This research was supported by Solus Advanced Materials Co., Ltd. (Yongin, Korea) and Holistic Bio Co., Ltd., Korea (Seongnam, Korea; Q2026771). Conceptualization: H. J. Suh and K. Jo; data curation: M. G. Kim; formal analysis: M. G. Kim and K. Jo; funding acquisition: Y. J. Choi and S. J. Lee; investigation: K. Jo; methodology: H. J. Suh; project administration: Y. Ahn; resources: Y. J. Choi and S. J. Lee; software: M. G. Kim; supervision: H. J. Suh and K. Jo; validation: Y. Ahn; visualization: M. G. Kim; writing-original draft: Y. Ahn, H. J. Suh, and K. Jo; writing-review and editing: Y. Ahn, M. G. Kim, Y. J. Choi, S. J. Lee, H. J. Suh, and K. Jo. The data that support the findings of this study are available from the corresponding author upon reasonable request. The authors have not stated any conflicts of interest. The funders had no role in the design of the study; in the collection, analyses, or interpretation of data; in the writing of the manuscript, or in the decision to publish the results.

\section{REFERENCES}

Ansary, T. M., M. R. Hossain, K. Kamiya, M. Komine, and M. Ohtsuki. 2021. Inflammatory molecules associated with ultraviolet radiation-mediated skin aging. Int. J. Mol. Sci. 22:3974. https:// doi.org/10.3390/ijms22083974.

Boer, M., E. Duchnik, R. Maleszka, and M. Marchlewicz. 2016. Structural and biophysical characteristics of human skin in maintaining proper epidermal barrier function. Postepy Dermatol. Alergol. 33:1-5. https://doi.org/10.5114/pdia.2015.48037.

Bouwstra, J. A., R. W. Helder, and A. El Ghalbzouri. 2021. Human skin equivalents: Impaired barrier function in relation to the lipid and protein properties of the stratum corneum. Adv. Drug Deliv. Rev. 175:113802. https://doi.org/10.1016/j.addr.2021.05.012.

Brod, J. 1991. Characterization and physiological role of epidermal lipids. Int. J. Dermatol. 30:84-90. https://doi.org/10.1111/j.1365 -4362.1991.tb04216.x.

Duan, J., T. Sugawara, M. Hirose, K. Aida, S. Sakai, A. Fujii, and T. Hirata. 2012. Dietary sphingolipids improve skin barrier functions via the upregulation of ceramide synthases in the epidermis. Exp. Dermatol. 21:448-452. https://doi.org/10.1111/j.1600-0625.2012 .01501.x.

Fisher, G. J., S. C. Datta, H. S. Talwar, Z. Q. Wang, J. Varani, S. Kang, and J. J. Voorhees. 1996. Molecular basis of sun-induced premature skin ageing and retinoid antagonism. Nature 379:335339. https://doi.org/10.1038/379335a0.

Fong, B. Y., C. S. Norris, and A. K. MacGibbon. 2007. Protein and lipid composition of bovine milk-fat-globule membrane. Int. Dairy J. 17:275-288. https://doi.org/10.1016/j.idairyj.2006.05.004.

Gao, W., Y.-S. Wang, E. Hwang, P. Lin, J. Bae, S. A. Seo, Z. Yan, and T.-H. Yi. 2018. Rubus idaeus L. (red raspberry) blocks UVB-induced MMP production and promotes type I procollagen synthesis via inhibition of MAPK/AP-1, NF- $\kappa \beta$ and stimulation of TGF- $\beta$ / Smad, Nrf2 in normal human dermal fibroblasts. J. Photochem. Photobiol. B 185:241-253. https://doi.org/10.1016/j.jphotobiol .2018.06.007.

Garg, A., and B. B. Aggarwal. 2002. Nuclear transcription factor-kappaB as a target for cancer drug development. Leukemia 16:10531068. https://doi.org/10.1038/sj.leu.2402482.

Geng, R., S.-G. Kang, K. Huang, and T. Tong. 2021. Boosting the photoaged skin: The potential role of dietary components. Nutrients 13:1691. https://doi.org/10.3390/nu13051691.

Graves, E. L. F., A. D. Beaulieu, and J. K. Drackley. 2007. Factors affecting the concentration of sphingomyelin in bovine milk. J. Dairy Sci. 90:706-715. https://doi.org/10.3168/jds.S0022-0302(07)71554 -0 .

Haruta-Ono, Y., S. Setoguchi, H. M. Ueno, S. Higurashi, N. Ueda, K. Kato, T. Saito, K. Matsunaga, and J. Takata. 2012a. Orally administered sphingomyelin in bovine milk is incorporated into skin sphingolipids and is involved in the water-holding capacity of hairless mice. J. Dermatol. Sci. 68:56-62. https://doi.org/10.1016/ j.jdermsci.2012.07.006.

Haruta-Ono, Y., H. Ueno, N. Ueda, K. Kato, and T. Yoshioka. 2012b. Investigation into the dosage of dietary sphingomyelin concentrate in relation to the improvement of epidermal function in hairless mice. Anim. Sci. J. 83:178-183. https://doi.org/10.1111/j.1740 $-0929.2011 .00940 . x$

Jeong, S. K., Y. I. Kim, K. O. Shin, B. W. Kim, S. H. Lee, J. E. Jeon, H. J. Kim, Y. M. Lee, T. M. Mauro, P. M. Elias, Y. Uchida, and K. Park. 2015. Sphingosine kinase 1 activation enhances epidermal innate immunity through sphingosine-1-phosphate stimulation of cathelicidin production. J. Dermatol. Sci. 79:229-234. https://doi .org/10.1016/j.jdermsci.2015.06.007.

Jin, Y.-J., Y. Ji, Y.-P. Jang, and S.-Y. Choung. 2021. Acer tataricum ssp. ginnala inhibits skin photoaging via regulating MAPK/AP1 , NF- $\kappa B$, and TGF $\beta /$ Smad signaling in UVB-irradiated human dermal fibroblasts. Molecules 26:662. https://doi.org/10.3390/ molecules26030662.

Jo, K. 2021. Supplementary Table 1.docx. figshare. Figure. https://doi .org/https://doi.org/10.6084/m9.figshare.17157776.v1. 
Kim, J., H. Yun, and Y. Cho. 2011. Analysis of ceramide metabolites in differentiating epidermal keratinocytes treated with calcium or vitamin C. Nutr. Res. Pract. 5:396-403. https://doi.org/10.4162/ nrp.2011.5.5.396.

Krutmann, J., S. Schalka, R. E. B. Watson, L. Wei, and A. Morita. 2021. Daily photoprotection to prevent photoaging. Photodermatol. Photoimmunol. Photomed. 37:482-489. https://doi.org/10 $.1111 /$ phpp. 12688 .

Lee, K., A. Kim, K. B. Hong, H. J. Suh, and K. Jo. 2020. Preparation and characterization of a polar milk lipid-enriched component from whey powder. Food Sci. Anim. Resour. 40:209-220. https:// doi.org/10.5851/kosfa.2020.e5.

Livak, K. J., and T. D. Schmittgen. 2001. Analysis of relative gene expression data using real-time quantitative PCR and the $2(\mathrm{~T})$ (-Delta Delta C) method. Methods 25:402-408. https://doi.org/10 $1006 /$ meth.2001.1262.

Lodén, M. 2012. Effect of moisturizers on epidermal barrier function. Clin. Dermatol. 30:286-296. https://doi.org/10.1016/j .clindermatol.2011.08.015.

Min, J. K., H. S. Yoo, E. Y. Lee, W. J. Lee, and Y. M. Lee. 2002. Simultaneous quantitative analysis of sphingoid base 1-phosphates in biological samples by o-phthalaldehyde precolumn derivatization after dephosphorylation with alkaline phosphatase. Anal. Biochem. 303:167-175. https://doi.org/10.1006/abio.2002.5579.

Mizutani, Y., S. Mitsutake, K. Tsuji, A. Kihara, and Y. Igarashi. 2009. Ceramide biosynthesis in keratinocyte and its role in skin function. Biochimie 91:784-790. https://doi.org/10.1016/j.biochi 2009.04.001.

Moon, S. H., J. Y. Kim, E. H. Song, M. K. Shin, Y. H. Cho, and N. I. Kim. 2013. Altered levels of sphingosine and sphinganine in psoriatic epidermis. Ann. Dermatol. 25:321-326. https://doi.org/ 10.5021/ad.2013.25.3.321.

Morifuji, M. 2019. The beneficial role of functional food components in mitigating ultraviolet-induced skin damage. Exp. Dermatol. 28:28-31. https://doi.org/10.1111/exd.13825.

Nisbet, S. J. 2018. Skin acceptability of a cosmetic moisturizer formulation in female subjects with sensitive skin. Clin. Cosmet. Investig. Dermatol. 11:213-217. https://doi.org/10.2147/CCID.S157297.

Ohlsson, L., E. Hertervig, B. A. Jönsson, R. D. Duan, L. Nyberg, R. Svernlöv, and A. Nilsson. 2010. Sphingolipids in human ileostomy content after meals containing milk sphingomyelin. Am. J. Clin. Nutr. 91:672-678. https://doi.org/10.3945/ajcn.2009.28311.

Park, K., P. M. Elias, K. O. Shin, Y. M. Lee, M. Hupe, A. W. Borkowski, R. L. Gallo, J. Saba, W. M. Holleran, and Y. Uchida. 2013. A novel role of a lipid species, sphingosine-1-phosphate, in epithelial innate immunity. Mol. Cell. Biol. 33:752-762. https://doi.org/10 $.1128 /$ MCB.01103-12.

Parodi, P. W. 1997. Cows' milk fat components as potential anticarcinogenic agents. J. Nutr. 127:1055-1060. https://doi.org/10 $.1093 /$ jn/127.6.1055.

Potočki, S. 2016. Potential health benefits of sphingolipids in milk and dairy products. Mljekarstvo 66:251-261. https://doi.org/10.15567/ mljekarstvo.2016.0401.

Robert, L., J. Labat-Robert, and A. M. Robert. 2009. Physiology of skin aging. Pathol. Biol. (Paris) 57:336-341. https://doi.org/10 .1016/j.patbio.2008.09.007

Schmelz, E. M., K. J. Crall, R. Larocque, D. L. Dillehay, and A. H. Merrill Jr.. 1994. Uptake and metabolism of sphingolipids in isolated intestinal loops of mice. J. Nutr. 124:702-712. https://doi .org/10.1093/jn/124.5.702.
Shimoda, H., S. Terazawa, S. Hitoe, J. Tanaka, S. Nakamura, H. Matsuda, and M. Yoshikawa. 2012. Changes in ceramides and glucosylceramides in mouse skin and human epidermal equivalents by rice-derived glucosylceramide. J. Med. Food 15:1064-1072. https:/ /doi.org/10.1089/jmf.2011.2137.

Simpson, E., A. Böhling, S. Bielfeldt, C. Bosc, and N. Kerrouche. 2013. Improvement of skin barrier function in atopic dermatitis patients with a new moisturizer containing a ceramide precursor. J. Dermatolog. Treat. 24:122-125. https://doi.org/10.3109/09546634 .2012.713461.

Suh, M. G., G. Y. Bae, K. Jo, J. M. Kim, K. B. Hong, and H. J. Suh. 2020. Photoprotective effect of dietary galacto-oligosaccharide (GOS) in hairless mice via regulation of the MAPK signaling pathway. Molecules 25:1679. https://doi.org/10.3390/ molecules25071679.

Tsuji, K., S. Mitsutake, J. Ishikawa, Y. Takagi, M. Akiyama, H. Shimizu, T. Tomiyama, and Y. Igarashi. 2006. Dietary glucosylceramide improves skin barrier function in hairless mice. J. Dermatol. Sci. 44:101-107. https://doi.org/10.1016/j.jdermsci.2006.08 .005 .

Uchida, Y., M. Hara, H. Nishio, E. Sidransky, S. Inoue, F. Otsuka, A. Suzuki, P. M. Elias, W. M. Holleran, and S. Hamanaka. 2000. Epidermal sphingomyelins are precursors for selected stratum corneum ceramides. J. Lipid Res. 41:2071-2082. https://doi.org/10 $.1016 /$ S0022-2275(20)32369-5.

Vávrová, K., A. Kováćik, and L. Opálka. 2017. Ceramides in the skin barrier. Eur. Pharm. J. 64:28-35. https://doi.org/10.1515/afpuc -2017-0004.

Vincenti, M. P., and C. E. Brinckerhoff. 2002. Transcriptional regulation of collagenase (MMP-1, MMP-13) genes in arthritis: Integration of complex signaling pathways for the recruitment of gene-specific transcription factors. Arthritis Res. Ther. 4:157-164. https://doi.org/10.1186/ar401.

Wartewig, S., and R. H. H. Neubert. 2007. Properties of ceramides and their impact on the stratum corneum structure: A review. Skin Pharmacol. Physiol. 20:220-229. https://doi.org/10.1159/ 000104420

Woodby, B., K. Penta, A. Pecorelli, M. A. Lila, and G. Valacchi. 2020. Skin health from the inside out. Annu. Rev. Food Sci. Technol. 11:235-254. https://doi.org/10.1146/annurev-food-032519-051722.

Yamamoto, T., M. Kurasawa, T. Hattori, T. Maeda, H. Nakano, and H. Sasaki. 2008. Relationship between expression of tight junction-related molecules and perturbed epidermal barrier function in UVB-irradiated hairless mice. Arch. Dermatol. Res. 300:61-68. https://doi.org/10.1007/s00403-007-0817-y.

Yamazaki, S., T. Muta, and K. Takeshige. 2001. A novel IkappaB protein, IkappaB-zeta, induced by proinflammatory stimuli, negatively regulates nuclear factor-kappaB in the nuclei. J. Biol. Chem. 276:27657-27662. https://doi.org/10.1074/jbc.M103426200.

\section{ORCIDS}

Yejin Ahn (ํ) https://orcid.org/0000-0002-7016-9798 Min G. Kim () https://orcid.org/0000-0001-8625-4957

Hyung J. Suh ๑ https://orcid.org/0000-0001-8869-3929

Kyungae Jo ๑ https://orcid.org/0000-0003-4056-6706 